\title{
Patterns and Pricing of Idiosyncratic Volatility in the French Stock Market
}

\author{
Zhentao Liu', Gilbert V. Nartea ${ }^{2}$, Ji Wu ${ }^{3^{*}}$ \\ ${ }^{1}$ Institute for Financial \& Accounting Studies, Xiamen University, Fujian, China \\ ${ }^{2}$ Department of Economics and Finance, UC Business School, University of Canterbury, Christchurch, New Zealand \\ ${ }^{3}$ School of Economics and Finance, Massey Business School, Massey University-Albany Campus, Auckland, New Zealand \\ Email:1zt@xmu.edu.cn, gilbert.nartea@canerbury.ac.nz, *j.wu1@massey.ac.nz
}

How to cite this paper: Liu, Z.T., Nartea, G.V. and Wu, J. (2018) Patterns and Pricing of Idiosyncratic Volatility in the French Stock Market. Theoretical Economics Letters, 8, 79-97.

https://doi.org/10.4236/tel.2018.81005

Received: July 19, 2017

Accepted: January 26, 2018

Published: January 29, 2018

Copyright $\odot 2018$ by authors and Scientific Research Publishing Inc. This work is licensed under the Creative Commons Attribution International License (CC BY 4.0).

http://creativecommons.org/licenses/by/4.0/

\begin{abstract}
We investigate the time series behavior of idiosyncratic volatility and its role in asset pricing in France. We find that both aggregate idiosyncratic and market volatility exhibit regime switching behavior similar to that in the U.S. and other developed countries. Furthermore, we find a marginally significant negative IVOL effect in the French stock market. We add new evidence to the mounting results questioning the ubiquity of the IVOL effect which highlights the importance of country verification of so called anomalies in the US, even in developed markets.
\end{abstract}

\section{Keywords}

Idiosyncratic Volatility, Regime Switch Model, Asset Pricing, France

\section{Introduction}

In a recent study, Ang et al. [1] confirm the ubiquity of a puzzling negative idiosyncratic volatility (IVOL) effect [1] in 23 developed countries, including the seven largest developed economies (G7) where high volatility stocks earn low risk-adjusted returns. This is puzzling because traditional finance theory suggests that idiosyncratic volatility should not be priced as it could be eliminated at no cost through diversification. In case investors cannot fully diversify, finance theory suggests a positive (not a negative) relationship between idiosyncratic risk and return [2] [3]. Ang et al. [4] report a statistically significant difference in risk-adjusted returns between high and low IVOL portfolios of $1.31 \%$ per month across 23 developed markets. ${ }^{1}$ However, in their study, they also report that ${ }^{1}$ However, some studies suggest that Ang et al.'s findings are not robust to portfolio weighting schemes [5] [6] and controls for short-term reversals [7]. Others argue that a positive relationship exists between idiosyncratic volatility and returns using alternative measures of expected idiosyncratic volatility [8] [9] [10] [11] [12]. 
among G7 countries not only did France show a decrease in the magnitude of the idiosyncratic volatility coefficient when idiosyncratic volatility was computed using a local Fama-French model instead of a world Fama-French model, but also the idiosyncratic volatility coefficient turned insignificant, indicating the absence of an IVOL effect. We investigate this further in this study. To the best of our knowledge, this is the first paper to examine the role of IVOL in pricing French stocks. If there is no significant relationship between returns and idiosyncratic volatility in the French stock market, this would add to mounting evidence questioning the ubiquity of the so called idiosyncratic volatility effect [5] [6] [11] [13]-[19].

Campbell et al. [20] report evidence of an increasing trend in idiosyncratic volatility in the U.S. relative to market volatility in the period 1962 to 1997. This is important since it implies increasing benefits from diversification. Theoretically, if there is an increasing trend in IVOL with a flat market volatility, investors would benefit from portfolio diversification. If IVOL has a decreasing trend or remains flat, then it is hard for investors to capture diversification benefits. In this sense, IVOL may not be priced in the stock market. However, Brandt, Brav, Graham, and Kumar [21] dispute Campbell et al.'s findings of an increasing trend, suggesting instead an episodic pattern in idiosyncratic volatility in the U.S. that is largely driven by the behavior of retail investors. In a related study Bekaert, et al. [22] show for the U.S. and in 22 other developed markets, that instead of a long-term trend, IVOL follows a stationary autoregressive process that occasionally switches to a higher variance regime. The trend in IVOL is an important issue relative to the benefit of portfolio diversification, hence our interest in the historical trend of IVOL in the French stock market, which is also the first evidence on this issue.

In this study, we investigate the behavior of aggregate idiosyncratic and market volatility from 1991 to 2012 in the French stock market. Then we examine the relationship between idiosyncratic volatility and cross-sectional stock returns. There are two reasons why we are interested in the IVOL effect in French stock market. First, most of the previous literature investigates trends and pricing behavior of IVOL in a group of European stock markets, but not in the French stock market on its own. The French stock market is one of the oldest stock markets in the world, and the $2^{\text {nd }}$ largest stock market ranked by capitalization in Europe following the U.K. stock market. Moreover, the French stock exchange was ranked the $4^{\text {th }}$ largest exchange in the world, with a total market capitalization of USD $\$ 3.5$ trillion in November 2014 [23]. Surprisingly, the French stock market as an individual sample has so far been ignored in the literature, especially in the fields of asset pricing and financial anomalies. Therefore, this study is going to fill the gap in the literature. Second, the French stock market, known as the Paris Bourse, has been restructured in September 2000, and it plays the role of a regional stock exchange rather than a stock exchange for an individual country. The early stage of the French stock exchange was comprised by three sections: the official list (the Premier Marché), the lists for me- 
dium-sized companies (the Second Marché), and the list for fast-growing start-up companies (the Nouveau Marché). In September 2000, the Paris Bourse merged with the Amsterdam, Lisbon and Brussels exchanges to form Euronext $\mathrm{NV}$ [24]. There are more than 1300 companies listed on the integrated exchange at moment. It would be interesting to test the IVOL effect for French listed firms only on a universal stock market after the consolidation of independent European markets since our testing period covers both periods.

We can easily summarize our results. First, we test for the presence of trends in aggregate idiosyncratic and market volatility using Bunzel and Vogelsang's [25] $t$-dan test. We also follow Bekaert et al.'s [22] method to further test for regime shifts. We find that both idiosyncratic and market volatility do not exhibit long-term trends. Instead, their patterns are consistent with regime switching behavior. Second, though we initially find a significant negative IVOL effect in the French stock market which is robust in bi-variate Fama-MacBeth regressions, the negative IVOL effect becomes marginally significant when we control for SIZE, BM, momentum, and short-term reversal simultaneously. Our new evidence suggests that there is a marginal IVOL effect in the French stock market adding to the increasing number of studies questioning the ubiquity of the negative IVOL puzzle.

We contribute to the literature on the idiosyncratic volatility effect in a number of ways. First, we present the first empirical evidence examining the trend in IVOL and its role in asset pricing in the French stock market. Prior studies mostly focused on a group of developed stock markets rather than on individual stock markets. Hence we draw attention for both academia and practitioners on an individual developed stock market. Second, we add new evidence to the mounting results questioning the ubiquity of the IVOL effect. This highlights the importance of country verification of so called anomalies in the US, even in developed markets. Next, we provide empirical evidence on the pricing of IVOL both at the portfolio and firm levels. Previous research only focuses on the role of pricing IVOL on either portfolio level or firm level. Therefore, our results are comprehensive and more convincing. Finally, we confirm earlier evidence that idiosyncratic volatility in the French stock market exhibits a regime switching behavior rather than showing a long-term time trend.

The rest of the paper is organized as follows: Section 2 describes our data and methods; Section 3 presents the empirical results in three parts. First we report volatility patterns over time, then we examine the relation between volatility and market returns, and finally we examine the relation between idiosyncratic volatility and cross-sectional stock returns. Section 4 concludes the paper.

\section{Data and Methods}

Although the French stock exchange represents a universal stock exchange in Europe which lists firms from different countries today, the sample of the current study only covers listed French firms. Daily and monthly stock returns on individual firms were obtained from DataStream. The data set covered the pe- 
riod from August 1991 with 147 firms, to June 2012 with 507 firms, with an average of 443 firms per month ${ }^{2}$. The risk-free rate which is defined as French EU-FRANCE 1 month middle rate was also obtained from the DataStream. Market returns are the value-weighted returns of all firms used in the study.

We exclude investment trusts, closed-end funds, exchange traded funds, and preferred shares. At the beginning of each month, we exclude stocks that do not have continuous return records in the past 22 trading days. In order to reduce noise in computing IVOL for each stock, we also exclude stocks with daily returns less than $-100 \%$ and/or monthly return greater than $200 \%$ as well as stocks with negative book-to-market (BM) ratio. Stocks with missing accounting data in a particular month were also excluded from the sample in that month.

\subsection{Estimating Idiosyncratic Volatility}

We follow Ang et al. [1] [4] and estimate the IVOL of each firm at the beginning of every month. IVOL is the standard deviation of the residuals $\left(\sigma_{\varepsilon i}\right)$ from the Fama-French [26] [27] 3-factor model (1), henceforth FF3-factor model, using daily data for the previous 22 trading days.

$$
R_{i, t}=\alpha+\beta_{M K T, i, m} M K T_{t}+\beta_{S M B, i, m} S M B_{t}+\beta_{H M L, i, m} H M L_{t}+\varepsilon_{i, t}
$$

where day $t$ refers to the 22 trading days ending on the last trading day of month $m-1 . R_{i, t}$ and $M K T$ are excess returns of firm $i$ and the market, respectively, over the risk-free rate. $S M B$ is the excess return of small firms over big firms, and $H M L$ is the excess return of high book-to-market (BM) firms over low BM firms. $S M B$ is the return of the upper half less the return of the lower half of all firms ranked in ascending order according to market capitalization while $H M L$ is the return of the bottom third less the return of the top third of all firms ranked in ascending order according to BM.

\subsection{Portfolio Analysis and Fama-MacBeth Regressions}

We use both portfolio-level analysis as well as firm-level Fama-MacBeth cross-sectional regressions to examine the relation between IVOL and expected returns. In portfolio-level analysis, firms are first sorted into tertiles at the start of each month based on IVOL and allocated to groups. We then compute each tertile portfolio's equal- and value-weighted raw returns for the current month. We also estimate each tertile portfolio's alpha ( $\alpha$ coefficient) from the FF3-factor model (Equation (1)) using each tertile portfolio's full sample of monthly valueor equal-weighted returns.

As a robustness test, we also conduct firm-level Fama-MacBeth regressions to control for various variables. We estimate the following model and its nested versions:

${ }^{2}$ The Appendix 1 shows the details of our sample stocks. The average numbers of share in the sample increased from 302 in 1992 to 685 in 2012. The highest annualized average return was 35\% in 1993 and the lowest level was $-66 \%$ in 2008 due to the global financial crisis. The annualized market capitalization doubled from 659.49 million dollars to 1490.94 million dollars between 1992 and 2012. Finally, the value of the BTM ranged from 0.60 to 1.32 in the sample period. 


$$
\begin{aligned}
R_{i, t+1}= & \beta_{0, t}+\beta_{1, t} I V_{i, t}+\beta_{2, t} \operatorname{SIZE}_{i, t}+\beta_{3, t} \text { Value }_{i, t} \\
& +\beta_{4, t} \operatorname{Reversal}_{i, t}+\beta_{5, t} \text { Momentum }_{i, t}
\end{aligned}
$$

$R_{t}$ is realized stock return in month $t$. IVOL is realized idiosyncratic volatility as defined previously. SIZE at the end of month $t$ is defined as the log of the firm's market capitalization at the end of month $t$. BM is the firm's book-to-market ratio six months prior, i.e. at the end of $t-6$. Following Jegadeesh and Titman [28], MOM at time $t$ is the stock's 11-month past return lagged one month, i.e. return from month $t-12$ to month $t-2$. REV in month $t$ is short-term reversal defined as the return on the stock in month $t-1$, following Jegadeesh [29] and Lehmann [30].

\section{Empirical Results}

\subsection{Volatility Patterns over Time}

\subsubsection{Descriptive Statistics}

We report the descriptive statistics for three volatility series in Table 1. MVOL is monthly market volatility (MVOL). The MVOL for a given month $m$ is the standard deviation of the daily value-weighted market returns for the past 22 trading days ending on the last trading day of month $m$. IVOL ${ }^{\mathrm{EW}}$ and $\mathrm{IVOL}^{\mathrm{VW}}$ are respectively the equal-weighted (EW) and value-weighted (VW) average idiosyncratic volatility across all firms, where IVOL is the standard deviation of residuals from (1). Table 1 shows that both $\mathrm{IVOL}^{\mathrm{EW}}$ and $\mathrm{IVOL}^{\mathrm{VW}}$ are 0.0188 and 0.0127 respectively, which is only about half compared to the IVOL in China, the biggest emerging stock market in the world [31]. The results support the view that stock markets in developed countries might be more stable than those in emerging stock markets. Moreover, the results also indicate that small firms seem to have higher idiosyncratic volatility than big firms as suggested by the higher mean of IVOL ${ }^{\mathrm{EW}}$ compared with IVOL ${ }^{\mathrm{VW}}$. This is consistent with results in other markets particularly the U.S. However, $\mathrm{IVOL}^{\mathrm{EW}}$ is less variable than $\mathrm{IVOL}^{\mathrm{VW}}$ as indicated by its lower coefficient of variation (CV). MVOL on the other hand is more variable than $\mathrm{IVOL}^{\mathrm{EW}}$ having a higher $\mathrm{CV}$, but it has a similar CV as IVOL ${ }^{\mathrm{Vw}}$.

As expected, our volatility measures are highly correlated as shown in Panel B, with correlation coefficients ranging from 0.849 to 0.913 .

Panel C displays the autocorrelation structure of the three volatility series. As serial correlation is fairly high in all three series, we test for the presence of unit roots using the augmented Dickey and Fuller [32] test. Panel D shows that we can reject the presence of unit roots for all three series, whether or not a trend is included. Hence our analysis of the volatility series will be in levels instead of first differences.

\subsubsection{Does a Time Trend Exist?}

Figure 1 plots $\mathrm{IVOL}^{\mathrm{EW}}, \mathrm{IVOL}^{\mathrm{VW}}$, and MVOL. As indicated in Figure 1, there does not appear to be any long-term trend in any of these volatility series. 
Table 1. Descriptive statistics. IVOL ${ }^{\mathrm{EW}}$, IVOL ${ }^{\mathrm{VW}}$ and MVOL, are respectively the equaland value-weighted idiosyncratic volatility and market volatility. The sample period is 1991: 08-2012: 06. At the beginning of every month, we compute IVOL of each firm as the standard deviation of the residuals of the FF3-factor model by using daily return data from the previous 22 trading days. We use the standard deviation of daily value-weighted market returns for the past 22 trading days ending on the last trading day of month to represent the MVOL. The Augmented Dickey-Fuller test for unit roots in Panel D are based on regressions with a constant, and regressions with a constant and a trend. The $1 \%$ critical values for the unit root test are -3.47 with a constant, and -4.01 with constant and a trend respectively.

\begin{tabular}{|c|c|c|c|c|c|c|}
\hline \multicolumn{7}{|c|}{ Panel A: Summary statistics } \\
\hline & Mean & Median & Stdev & $\mathrm{CV}$ & MAX & Min \\
\hline$I V O L^{E W}$ & 0.0188 & 0.0174 & 0.0048 & 0.2553 & 0.0397 & 0.0120 \\
\hline$I V O L^{V W}$ & 0.0127 & 0.0113 & 0.0043 & 0.3386 & 0.0322 & 0.0074 \\
\hline$M V O L$ & 0.0184 & 0.0165 & 0.0067 & 0.3641 & 0.0582 & 0.0098 \\
\hline \multicolumn{7}{|c|}{ Panel B: Correlation Table } \\
\hline & $I V O L^{E W}$ & $I V O L^{V W}$ & $M V O L$ & & & \\
\hline$I V O L^{E W}$ & 1.0000 & & & & & \\
\hline$I V O L^{V W}$ & 0.8528 & 1.0000 & & & & \\
\hline$M V O L$ & 0.8489 & 0.9130 & 1.0000 & & & \\
\hline \multicolumn{7}{|c|}{ Panel C: Autocorrelation structure } \\
\hline & $I V O L^{E W}$ & $I V O L^{V W}$ & $M V O L$ & & & \\
\hline$\rho_{1}$ & 0.843 & 0.815 & 0.775 & & & \\
\hline$\rho_{2}$ & 0.748 & 0.727 & 0.607 & & & \\
\hline$\rho_{3}$ & 0.702 & 0.681 & 0.504 & & & \\
\hline$\rho_{4}$ & 0.621 & 0.615 & 0.422 & & & \\
\hline$\rho_{6}$ & 0.545 & 0.552 & 0.371 & & & \\
\hline$\rho_{12}$ & 0.451 & 0.373 & 0.224 & & & \\
\hline \multicolumn{7}{|c|}{ Panel D: Unit root test t-statistics } \\
\hline & Constant & Constan & Trend & & & \\
\hline$I V O L^{E W}$ & -4.6134 & -4.6588 & & & & \\
\hline$I V O L^{V W}$ & -3.9604 & -3.9728 & & & & \\
\hline$M V O L$ & -5.5268 & -5.5271 & & & & \\
\hline
\end{tabular}

Instead, the plots suggest episodic behavior in these series. There was an upward trend in all three volatility series from 1991 to 2001, a downward trend until 2006, a spike in 2009 followed by a decreasing trend thereafter. The pattern of our volatility measures in Figure 1 are very similar to the volatility figures for the French stock market reported by Duncan and Kabundi [33].

As a formal test for the presence of trends, we begin by estimating the following OLS model: 


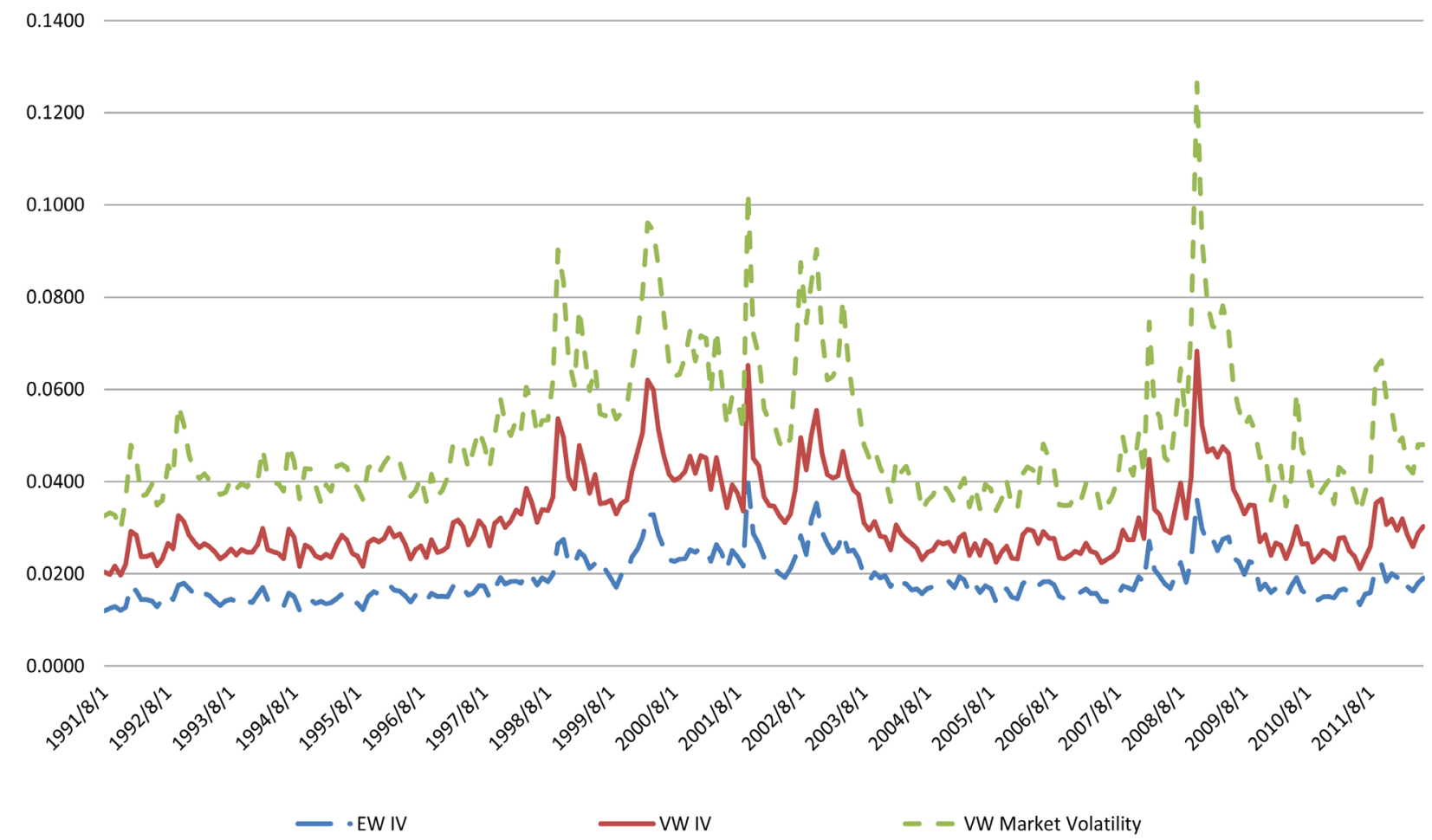

Figure 1. Volatility Series for French Stock Market. This figure plots the monthly equal-and value-weighted idiosyncratic volatility and the value-weighted market volatility. The sample period is 1991: 08 to 2012: 05.

$$
V O L_{t}=b_{0}+b_{1} t+b_{2} V O L_{t-1}+\varepsilon_{t}
$$

where VOL represents IVOL ${ }^{\mathrm{EW}}$, IVOL ${ }^{\mathrm{VW}}$, and MVOL, and $t$ is time. The estimated time trend $b_{1}$ parameter and its t-statistic are reported in Table 2. Over the full sample period from 1991: 08 to 2012: 06, the standard t-test shows a statistically significant positive trend in $\mathrm{IVOL}^{\mathrm{EW}}$ but no trend for both IVOL ${ }^{\mathrm{VW}}$ and MVOL. However, Vogelsang [34] points out that when errors in the trend regression are persistent, the student $t$-value often rejects the null hypothesis of no trend. As a consequence Bunzel and Vogelsang [25] developed the t-dan test which we employ in this study. ${ }^{3}$ This test is valid whether or not a unit root exists in the error terms. The t-dan test also has better power than the standard t-test while retaining its good size properties. The $t$-dan test statistics reported in Table 2 confirm the absence of a trend in either IVOL ${ }^{\mathrm{VW}}$ or MVOL but a positive trend in $\mathrm{IVOL}^{\mathrm{EW}}$ which indicates that the IVOL of small stocks have been trending upwards. However, this apparent trend in $\mathrm{IVOL}^{\mathrm{EW}}$ could be simply due to the spike in volatility towards the end of 2008. Nonetheless, the fact that MVOL and IVOL ${ }^{\mathrm{VW}}$ are relatively flat over the study period, implies that there is also no trend in correlations among stocks and that the benefits from diversification would have likely remained the same on average over the study period, which also means that the number of stocks needed to attain a certain level of diversification would also have remained the same.

${ }^{3}$ We thank Bert Ward for coding the $\mathrm{t}$-dan test. 
Table 2. Time trend of volatility series. We run the following model by regressing the volatility measure on its first lag and a time trend: $V O L_{t}=b_{0}+b_{1} t+b_{2} V O L_{t-1}+\varepsilon_{t}$ where $V O L$ represents $\mathrm{IVOL}^{\mathrm{EW}}, N \mathrm{NOL}^{\mathrm{VW}}$, and MVOL, and $t$ is time. The estimated time trend $b_{i}$ parameter and its t-statistic and the Bunzel and Vogelsang [25] t-dan test statistic for the full sample period are reported in Table 2 . The $5 \%$ critical value (two-sided) for $\mathrm{t}$-dan is 1.726 .

\begin{tabular}{cccc}
\hline \multicolumn{4}{c}{$1991.08-2012.06$} \\
\hline \\
\hline Linear Trend $\left(\times 10^{-5}\right)$ & t-stat & t-dan \\
\hline$I V O L^{E W}$ & 1.6107 & 3.9417 & 1.8160 \\
$M V O L$ & -2.2946 & -0.6191 & -0.2712 \\
& 0.9200 & 1.5750 & 1.0494 \\
\hline
\end{tabular}

\subsubsection{Regime Switching Behavior in Idiosyncratic Volatility}

In this section, we test for regime-switching behavior in idiosyncratic volatility. We follow Bekaert et al.'s [22] method to further test whether or not our volatility series in the French stock market is characterized by a stationary process that occasionally switches between high- and low-volatility regimes. Bekaert et al. [22] argue that the upward trends of idiosyncratic volatility in the U.S. and 22 other developed markets were driven by the chosen starting- and ending time points. For example, if the starting point is in a low volatility period, while the end point is in a high volatility period, then the trend test would easily show a positive trend. Bekaert et al. [22] thus suggest that idiosyncratic volatility in the U.S. and 22 other developed markets are best characterized by a stationary process that occasionally switches between high- and low-volatility regimes. A regime-switching behavior in idiosyncratic volatility also appears evident in emerging markets with Nartea, et al. [35] documenting evidence of such behavior in the Chinese stock market, the world's largest emerging market.

To test for regime switching behavior in idiosyncratic volatility in the French stock market, we let volatility, $y_{p}$ follow an $\mathrm{AR}(1)$ model where all parameters can take on one of two values depending on the realization of a discrete regime variable, $s_{t}$ The regime variable follows a Markov chain with constant transition probabilities. Indexing the current regime by $i$ the model is

$$
y_{t}=\left(1-b_{i}\right) \mu_{i}+b_{i} y_{t-1}+\sigma_{i} e_{t}, \quad i \in\{0,1\}
$$

with $e_{t} \sim N(0,1)$. In the model, we force regime 0 (regime 1) to be the low (high) volatility regime and the mean levels $\left(\mu_{i}\right)$ of the volatility series of both regimes to be nonnegative (i.e. $\mu_{1}>\mu_{0}>0$ ).

The transition probability matrix, $\Phi$, is $2 \times 2$, where each probability represents $P[s t=i \mid s t-1=j]$, with $i, j \in\{1,2\}$ :

$$
\Phi=\left(\begin{array}{cc}
p 11 & 1-p 11 \\
1-p 22 & p 22
\end{array}\right)
$$

The model has only 8 parameters, $\left\{\mu_{0}, \mu_{1}, b_{0}, b_{1}, \sigma_{0}, \sigma_{1}, p 11, p 22\right\}$.

The estimation results for each volatility series $\left(y_{t}=I V O L^{E W}, I V O L^{V W}\right.$, and $M V O L$ ) are reported in Table 3. We use the robust White (1980) covariance 
Table 3. Regime switching model estimation results. We report the regime-switching model results for the three volatility series. The model is:

$y_{t}=\left(1-b_{i}\right) \mu_{i}+b_{i} y_{t-1}+\sigma_{i} e_{t}, \quad i \in\{0,1\}$ The transition probability matrix is:

$\Phi=\left(\begin{array}{cc}p 11 & 1-p 11 \\ 1-p 22 & p 22\end{array}\right)$ The transition probability parameters, $p 11$ and $p 22$, are constrained to be in $(0,1)$ over the study period. We also reparameterize to ensure $\mu_{2}>\mu_{1}>0$. The estimation period is over 1991.08 to 2012.06. T-statistics are reported in parenthesis.

\begin{tabular}{|c|c|c|c|c|c|c|}
\hline & \multicolumn{2}{|c|}{$I V O L^{E W}$} & \multicolumn{2}{|c|}{$I V O L^{V W}$} & \multicolumn{2}{|c|}{$M V O L$} \\
\hline & Coeff. & Stan. Error & Coeff. & Stan. Error & Coeff. & Stan. Error \\
\hline$p 11$ & $\begin{array}{c}0.9566 \\
(51.9802)\end{array}$ & 0.0184 & $\begin{array}{c}0.9359 \\
(20.4997)\end{array}$ & 0.0457 & $\begin{array}{c}0.5898 \\
(5.3824)\end{array}$ & 0.1096 \\
\hline$p 22$ & $\begin{array}{c}0.8497 \\
(11.4633)\end{array}$ & 0.0741 & $\begin{array}{c}0.9762 \\
(58.2982)\end{array}$ & 0.0167 & $\begin{array}{c}0.8974 \\
(28.3458)\end{array}$ & 0.0317 \\
\hline$\sigma_{0}$ & $\begin{array}{c}0.0013 \\
(14.8685)\end{array}$ & 0.0001 & $\begin{array}{c}0.0013 \\
(16.4254)\end{array}$ & 0.0001 & $\begin{array}{c}0.0018 \\
(14.7378)\end{array}$ & 0.0001 \\
\hline$\sigma_{1}$ & $\begin{array}{c}0.0040 \\
(9.4579)\end{array}$ & 0.0004 & $\begin{array}{c}0.0035 \\
(11.7100)\end{array}$ & 0.0003 & $\begin{array}{c}0.0064 \\
(9.4864)\end{array}$ & 0.0007 \\
\hline$b_{0}$ & $\begin{array}{c}0.4815 \\
(3.6061)\end{array}$ & 0.1335 & $\begin{array}{c}0.6497 \\
(11.0250)\end{array}$ & 0.0589 & $\begin{array}{c}0.6357 \\
(26.9328)\end{array}$ & 0.0236 \\
\hline$b_{1}$ & $\begin{array}{c}0.7600 \\
(19.2827)\end{array}$ & 0.0394 & $\begin{array}{c}0.4810 \\
(4.2974)\end{array}$ & 0.1119 & $\begin{array}{c}0.6902 \\
(3.3680)\end{array}$ & 0.2049 \\
\hline$\mu_{0}$ & $\begin{array}{c}0.0258 \\
(20.1068)\end{array}$ & 0.0013 & $\begin{array}{c}0.0105 \\
(36.1627)\end{array}$ & 0.0003 & $\begin{array}{c}0.0147 \\
(34.8796)\end{array}$ & 0.0004 \\
\hline$\mu_{1}$ & $\begin{array}{c}0.0163 \\
(36.9071)\end{array}$ & 0.0004 & $\begin{array}{c}0.0181 \\
(19.0951)\end{array}$ & 0.0010 & $\begin{array}{c}0.0355 \\
(4.0839)\end{array}$ & 0.0087 \\
\hline Likelihood & \multicolumn{2}{|c|}{-1205.3056} & \multicolumn{2}{|c|}{-1216.8193} & \multicolumn{2}{|c|}{-1103.8582} \\
\hline
\end{tabular}

to compute the standard errors. Table 3 shows that levels for both EW and VW IVOL in the low volatility regime $\left(\mu_{0}\right)$ at $0.0258\left(\mathrm{IVOL}^{\mathrm{EW}}\right)$ and $0.0105\left(\mathrm{IVOL}^{\mathrm{VW}}\right)$ respectively, which are both statistically significant. The corresponding levels in the high volatility regime $\left(\mu_{1}\right)$ at 0.0163 and 0.0181 are also both statistically significant. The differences between the levels of the two regimes for both volatility series are also statistically significant as indicated by the results of the Wald test. Our results also show higher volatility in regime $1\left(\sigma_{1}\right)$ compared with regime 0 $\left(\sigma_{0}\right)$ for both EW and VW IVOL. The EW (VW) volatility in regime 1 is 0.0040 (0.0035) compared with 0.0013 (0.0013) for regime 0 . Thus we find that idiosyncratic volatility in the French stock market conforms with a stationary autoregressive process that occasionally switches between high and low-variance regimes. This is consistent with the behavior of idiosyncratic volatility in developed stock markets [22] and in the world's largest emerging market [35].

Figure 2 shows the smoothed probabilities of being in regime 0 for our three volatility series. Unlike the evidence reported by Bekaert et al. [22] in the U.S. stock market, we find that both high- and low-idiosyncratic volatility regimes in the French stock market have the propensity to stay for a period before switching to another. We observe this phenomenon several times over the study period. For example, Panel a of Figure 2 shows that $\mathrm{IVOL}^{\mathrm{EW}}$ was in a high 
Panel a Monthly Equal-weighted Idiosyncratic Volatility

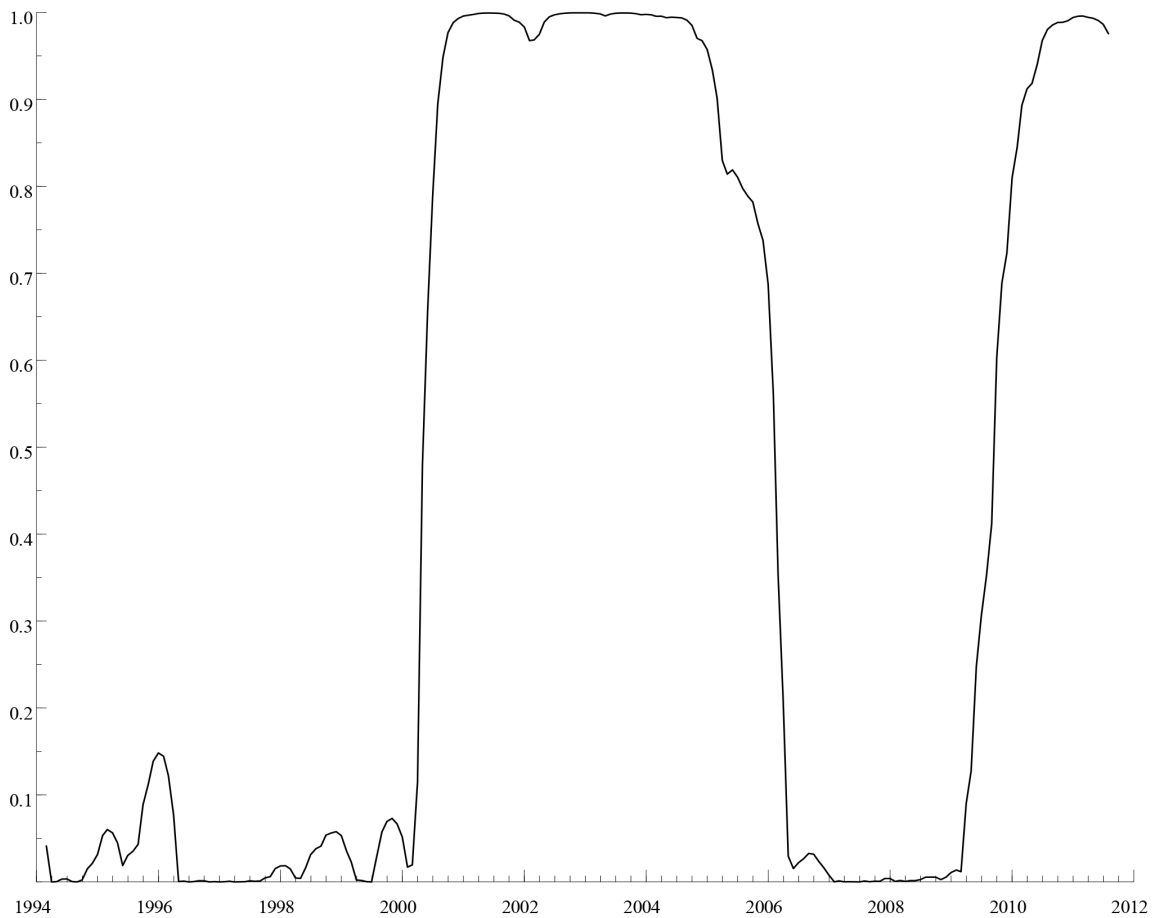

(a)

Panel b Monthly Value-weighted Idiosyncratic Volatility

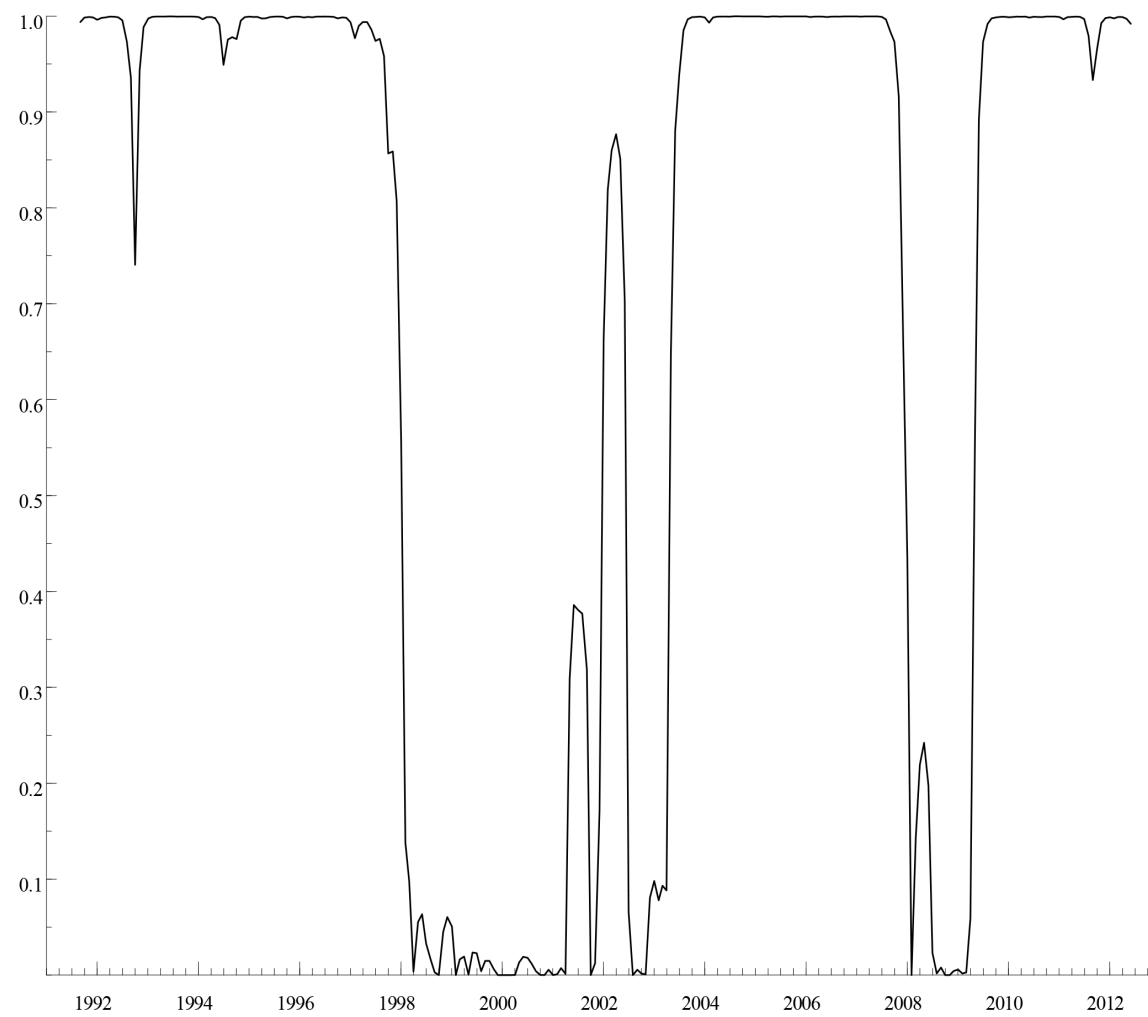

(b) 


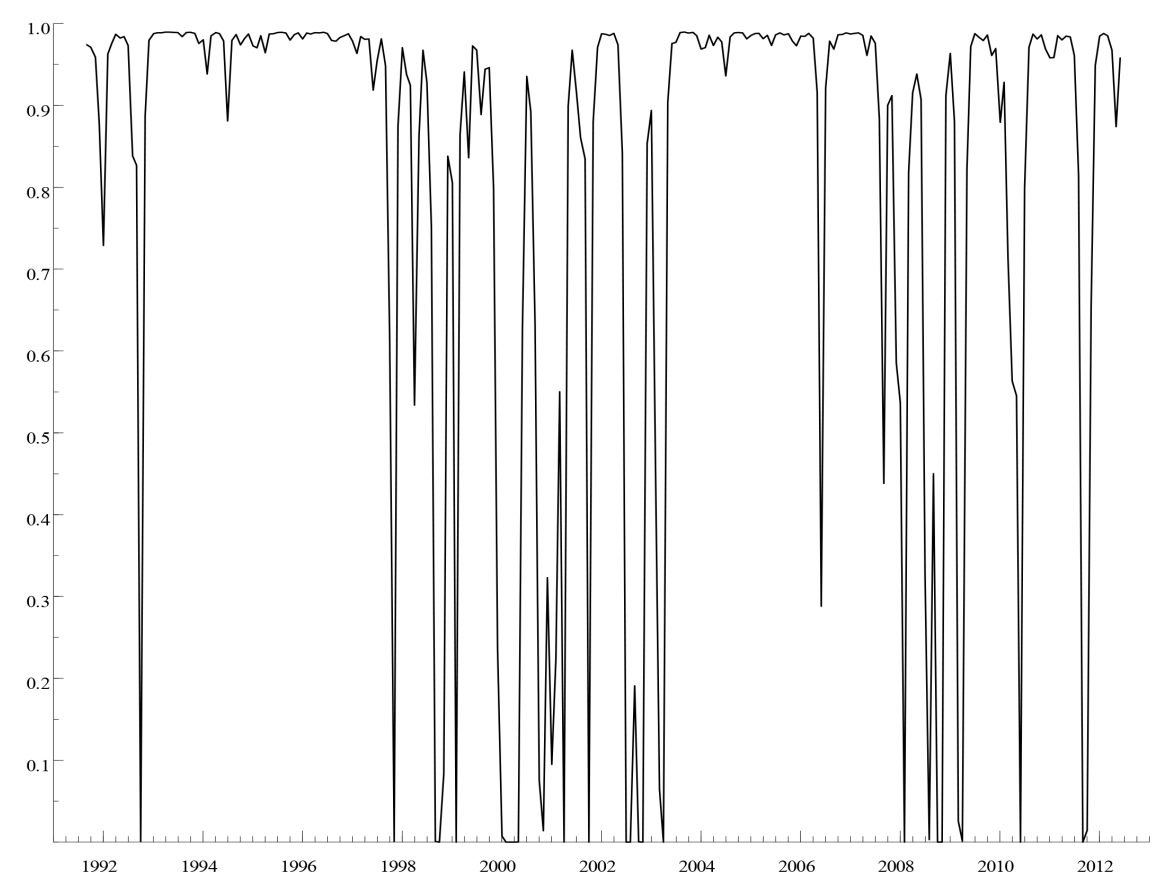

(c)

Figure 2. Smoothed probabilities of being in the low volatility regime (regime 0 ). The figure shows the smoothed probability of being in regime 0 for French, using a regime-switching model reported in Equation (4). The model is estimated over sample period 1991 to 2012 .

volatility regime from 1992 to mid-2000, consistent with Morel's [36] findings in the French stock market. And then, it shifts to a low volatility regime until the early of 2006. Furthermore, the $\mathrm{IVOL}^{\mathrm{EW}}$ remained in a high volatility regime during the 2008 financial crisis, until the beginning of 2009 when it switched again to a low volatility regime. Panel b of Figure 2 shows that IVOL ${ }^{\mathrm{VW}}$ switched between high- and low volatility regimes more frequently than IVOL ${ }^{\mathrm{EW}}$. IVOL ${ }^{\mathrm{VW}}$ stayed in the low volatility regime for most of the 20 year testing period, for example from 1992 to March 1998, January 2003 to January 2008, and September 2009 to the end of the study period. If we define $y_{t}$ to be in regime 0 if the probability of being in regime 0 is higher than 0.5 , and vice versa for regime 1 , then there are 4 regime switches in $\mathrm{IVOL}^{\mathrm{VW}}$ and 3 regime switches in $\mathrm{IVOL}^{\mathrm{EW}}$ over the 20-year study period. Our results indicate that big firms have become more volatile after the integration of the European stock market, but the volatily of small firms seem to becoming more stable. The results are consistent with Bekaert and Harvey's (2000) suggestion that market liberalization could not only reduce the volatility in emerging markets, but also in developed stock markets. Panel c of Figure 2 shows that MVOL was switching from low volatility regime to high volatility regime unpredictably over the study period. It is hard to observe a clear pattern for the MVOL, but the regime of the MVOL partly follows 
the regime of $\mathrm{IVOL}^{\mathrm{VW}}$ reported in the panel b.

Figure 2 confirms an insignificant time series trend in IVOL in the French stock market consistent with results reported in Table 2. For example, the absence of a trend in both $\mathrm{IVOL}^{\mathrm{VW}}$ and MVOL reported in Table 2 is consistent with both panels $\mathrm{b}$ and $\mathrm{c}$ in Figure 2, where both series start and end in the low volatility regimes over our study period. Panel a of Figure 2 shows that our testing period starts from a high-level of IVOL and ends in a low-level of IVOL, which indicates that the significant positive trend in $\mathrm{IVOL}^{\mathrm{EW}}$ reported in Table 2 is not due to the choice of sample period. However, results reported in Table 3 still suggest a significant regime-switching behavior for $\mathrm{IVOL}^{\mathrm{EW}}$.

We also find it interesting that $\mathrm{IVOL}^{\mathrm{VW}}$ and $\mathrm{IVOL}^{\mathrm{EW}}$ exhibit a divergence in the period from 1992 to 1999 , with $\mathrm{IVOL}^{\mathrm{EW}}$ being on a high-volatility regime while $\mathrm{IVOL}^{\mathrm{VW}}$ was on a low-volatility regime. We suggest that this could be due to the boom in high-tech stocks over this period. As high-tech stocks are normally smaller in size and more volatile than traditional listed firms, we expect $\mathrm{IVOL}^{\mathrm{EW}}$ to be more volatile than $\mathrm{IVOL}^{\mathrm{VW}}$ before the high-tech bubble burst around year 2000. We also find that both $\mathrm{IVOL}^{\mathrm{VW}}$ and $\mathrm{IVOL}^{\mathrm{EW}}$ were on a high volatility regime during the recent 2008 financial crisis. This is consistent with previous findings in the literature wherein stock markets are more volatile during the financial crisis period than other periods [35]. Finally, we find that both $\mathrm{IVOL}^{\mathrm{VW}}$ and $\mathrm{IVOL}^{\mathrm{EW}}$ show a convergent behavior after 2002 in the French stock market.

In sum, the results from Table 3 and Figure 2 indicate evidence of episodic behavior in all three volatility series, consistent with occasional regime shifts throughout the study period.

\subsection{Can Idiosyncratic Volatility Predict Cross-Sectional Expected Stock Returns?}

\subsubsection{Portfolio-Level Analysis}

In this section we examine the presence of an IVOL effect in the French stock market. Table 4 shows the average monthly returns and FF-3 alpha of EW and VW portfolios sorted according to idiosyncratic volatility. Though both the EW and VW return spreads between high and low IVOL portfolios are consistently negative at $-0.91 \%$ and $-0.71 \%$ per month respectively, they are not statistically significant. We only report the FF-3 alpha of each portfolio in the third column. Stotz et al. [36] report that there are not big differences between Fama and French's alpha and Jensen's alpha. The EW alpha spread is likewise negative at $-0.34 \%$ per month but also statistically insignificant. The exception is the statistically significant VW alpha spread at $-0.58 \%$ per month. This appears to be consistent with the anomalous and puzzling evidence documented by Ang et al. [1] [4] and Brockman and Yan [37] for the U.S. market. However it is not as high as the $-1.31 \%$ per month reported by Ang et al. [1] for the U.S.

Before we test the robustness of this apparent negative IVOL effect in the French stock market, we report the average of the monthly averages of various 
Table 4. Returns of portfolios sorted by idiosyncratic volatility. Stock portfolios have been sorted by IVOL at the beginning of every month, i.e., high IVOL (HIV), medium IVOL (MIV) and low IVOL (LIV). The table thus reports each portfolio's equal- and value-weighted raw returns for the current month. Each portfolio's alpha ( $\alpha$ coefficient) is also included in the table, which is from the FF3-factor model estimated using the full sample of monthly value- or equal-weighted returns for each portfolio. The last row presents the difference in monthly raw returns and differences in alpha between the high and low IVOL portfolios. T-statistics are reported in parenthesis.

\begin{tabular}{|c|c|c|c|c|}
\hline & \multirow[b]{2}{*}{ Mean } & \multirow{2}{*}{$\begin{array}{l}\text { Raw Return } \\
\text { Std. Dev }\end{array}$} & \multicolumn{2}{|c|}{ FF-3 Alpha } \\
\hline & & & Mean & Std. Error \\
\hline \multicolumn{5}{|c|}{ Equal-weighted } \\
\hline High IVOL & $\begin{array}{c}-0.0030 \\
(-0.6170)\end{array}$ & 0.0059 & $\begin{array}{c}-0.0003 \\
(-1.1118)\end{array}$ & 0.0026 \\
\hline Medium IVOL & $\begin{array}{c}0.0027 \\
(0.7707)\end{array}$ & 0.0030 & $\begin{array}{c}0.0010 \\
(0.5384)\end{array}$ & 0.0018 \\
\hline Low IVOL & $\begin{array}{c}0.0061 \\
(2.3879)\end{array}$ & 0.0016 & $\begin{array}{c}0.0031 \\
(2.3995)\end{array}$ & 0.0013 \\
\hline High-Low & $\begin{array}{c}-0.0091 \\
(-1.6526)\end{array}$ & & $\begin{array}{c}-0.0034 \\
(-1.1696)\end{array}$ & 0.0029 \\
\hline \multicolumn{5}{|c|}{ Value-weighted } \\
\hline High IVOL & $\begin{array}{c}-0.0019 \\
(-0.3658)\end{array}$ & 0.0070 & $\begin{array}{c}-0.0039 \\
(-2.0721)\end{array}$ & 0.0019 \\
\hline Medium IVOL & $\begin{array}{c}0.0028 \\
(0.7288)\end{array}$ & 0.0038 & $\begin{array}{c}-0.0008 \\
(-0.7252)\end{array}$ & 0.0011 \\
\hline Low IVOL & $\begin{array}{c}0.0051 \\
(1.5867)\end{array}$ & 0.0026 & $\begin{array}{c}0.0019 \\
(3.4614)\end{array}$ & 0.0006 \\
\hline High-Low & $\begin{array}{c}-0.0071 \\
(-1.1363)\end{array}$ & & $\begin{array}{c}-0.0058 \\
(-2.9109)\end{array}$ & 0.0020 \\
\hline
\end{tabular}

characteristics of the IVOL-sorted portfolios in Table 5. We report values for IVOL, size (SIZE), BM (Value), momentum (MOM), and short-term reversal (REV). These variables are as defined previously. The high IVOL portfolio has three times as much IVOL as the low IVOL portfolio and the difference is highly statistically significant as expected. High (low) IVOL stocks also tend to be small (big) stocks. These results are consistent with Drew et al's [38] findings in the German and UK stock markets, where they find that small firms have higher IVOLs than big firms. High (low) IVOL stocks also tend to be previous losers (winners) in the past 11 months. However, there is no significant difference in the value and short-term reversal variables between high and low IVOL portfolios. We formally control these variables using firm-level cross-sectional regressions in the next section.

\subsubsection{Firm-Level Cross-Sectional Regressions}

We begin with univariate regressions on IVOL and our control variables. Table 6 reports the time-series averages of the slope coefficients over the 251 months from 1991:08 to 2012:06 with Newey-West [39] t-statistics in parenthesis. The univariate regression shows a statistically significant negative relation between IVOL and the cross-section of one-month ahead stock returns. The results also 
Table 5. Characteristics of portfolios sorted by idiosyncratic volatility. The table shows that average firm's characteristics of each IVOL sorted portfolio over the full sample period, i.e., high IVOL (HIV), medium IVOL (MIV) and low IVOL (LIV). IVOL is the standard deviation of the residuals of the FF3-factor model computed using the past 22 trading daily returns data. SIZE is the firms' capitalization at the end of month $t$; Value is the firm's book-to-market ratio six months prior, i.e. at the end of $t$ - 6 . Momentum represents the stock's 11-month past return lagged one month by following Jegadeesh and Titman [28], i.e. return from month $t-12$ to month $t-2$. REV in month $t$ is short-term reversal defined as the return on the stock in month $t$-1, following Jegadeesh [29] and Lehmann [30]. T-statistics are reported in parenthesis.

\begin{tabular}{cccccc}
\hline & IVOL & SIZE & Value & Momentum & REV \\
\hline \multirow{2}{*}{ High IVOL } & 0.0303 & 575.82 & 0.8218 & -0.0394 & 0.0044 \\
& $(55.7154)$ & $(23.9111)$ & $(37.8627)$ & $(-1.5912)$ & $(0.7793)$ \\
Medium IVOL & 0.0166 & 1810.59 & 0.7864 & 0.0638 & 0.0022 \\
& $(61.3300)$ & $(32.4654)$ & $(48.2870)$ & $(4.1401)$ & $(0.6770)$ \\
Low IVOL & 0.0095 & 3717.68 & 0.8385 & 0.0924 & 0.0004 \\
& $(69.2589)$ & $(33.1339)$ & $(76.4216)$ & $(8.9538)$ & $(0.2133)$ \\
High-Low & 0.0208 & -3141.86 & -0.0200 & -0.1318 & 0.0040 \\
& $(37.1756)$ & $(-27.3784)$ & $(-0.8192)$ & $(-4.9116)$ & $(0.6716)$ \\
\hline
\end{tabular}

Table 6. Univariate Fama-Macbeth regression results. We perform firm-level Fama-MacBeth cross-sectional regressions on the return on that month with values of the control variables in the previous month for the full sample period. The time-series averages of the slope coefficients and their associated t-statistics are reported in the table. IVOL is the standard deviation of the residuals of the FF3-factor model computed using the past 22 trading daily returns data. SIZE is the firms' capitalization at the end of month $t$; Value is the firm's book-to-market ratio six months prior, i.e. at the end of $t$-6. Momentum represents the stock's 11-month past return lagged one month by following Jegadeesh and Titman [28], i.e. return from month $t$-12 to month $t-2$. REV in month $t$ is short-term reversal defined as the return on the stock in month $t-1$, following Jegadeesh [29] and Lehmann [30]. Newey-West T-statistics are reported in parenthesis. $R_{i, t+1}=\beta_{0, t}+\beta_{1, t} I V_{i, t}+\beta_{2, t} M V_{i, t}+\beta_{3, t}$ Value $_{i, t}+\beta_{4, t}$ Reversal $_{i, t}+\beta_{5, t}$ Momentum $_{i, t}$.

\begin{tabular}{cccccc}
\hline Intercept & IVOL & SIZE & Value & Reversal & Momentum \\
\hline 0.0117 & -0.6322 & & & \\
$(3.10)$ & $(-3.08)$ & & & & \\
0.0017 & & $1.16 \mathrm{E}-7$ & & & \\
$(0.48)$ & & $(0.68)$ & & & \\
-0.0035 & & 0.0072 & & \\
$(-0.72)$ & & $(3.75)$ & & \\
0.0022 & & & -0.0135 & \\
$(0.53)$ & & & $(-1.02)$ & \\
0.0005 & & & & 0.0159 \\
$(0.15)$ & & & & \\
\hline
\end{tabular}

show significant momentum and BM effects with previous winners and stocks with high BM exhibiting higher returns. However we find no size and short-term reversal effects. The absence of a size effect is consistent with Morel [40] who reports a significant size effect from March 1996 to July 1996 which disappears thereafter. 
Table 7. Bivariate and multivariate Fama-Macbeth regression results. We perform a firm-level Fama-MacBeth cross-sectional regression of the return on that month with values of the control variables in previous month for the full sample period. The time-series averages of the slope coefficients and their associated t-statistics are reported in the table. IVOL is the standard deviation of the residuals of the FF3-factor model computed using the past 22 trading daily returns data. SIZE is the firms' capitalization at the end of month $t$, Value is the firm's book-to-market ratio six months prior, i.e. at the end of $t-6$. Momentum represents the stock's 11-month past return lagged one month by following Jegadeesh and Titman [28], i.e. return from month $t-12$ to month $t-2$. REV in month $t$ is short-term reversal defined as the return on the stock in month $t-1$, following Jegadeesh [29] and Lehmann [30]. Newey-West T-statistics are reported in parenthesis. $R_{i, t+1}=\beta_{0, t}+\beta_{1, t} I V_{i, t}+\beta_{2, t} M V_{i, t}+\beta_{3, t}$ Value $_{i, t}+\beta_{4, t}$ Reversal $_{i, t}+\beta_{5, t}$ Momentum $_{i, t}$.

\begin{tabular}{cccccc}
\hline Intercept & IVOL & SIZE & Value & Reversal & Momentum \\
\hline 0.0130 & -0.7141 & $-5.93 \mathrm{E}-8$ & & & \\
$(3.03)$ & $(-2.92)$ & $(-0.35)$ & & & \\
0.0056 & -0.5235 & & 0.0063 & & \\
$(1.52)$ & $(-3.14)$ & & $(3.99)$ & & \\
0.0098 & -0.4504 & & & -0.0164 & \\
$(2.83)$ & $(-3.12)$ & & $(-1.39)$ & \\
0.0093 & -0.5830 & & & & \\
$(2.35)$ & $(-2.82)$ & & & & \\
0.0021 & -0.4454 & $4.97 \mathrm{E}-9$ & 0.0063 & -0.0495 & 0.02142 \\
$(0.49)$ & $(-1.75)$ & $(0.03)$ & $(4.99)$ & $(-3.68)$ & $(5.07)$ \\
\hline
\end{tabular}

Next we control the size, BM, reversal, and momentum effects individually with bi-variate Fama-MacBeth cross-sectional regressions and then simultaneously in a multivariate regression. We report the results in Table 7 . The bivariate regressions show that none of our control variables can individually explain the negative IVOL effect. However if we control for all four variables simultaneously, the IVOL coefficient becomes insignificant! Therefore, firm-level cross-sectional regression results indicate that the apparent negative IVOL effect in the French stock market is not robust and can be explained by our control variables.

\section{Concluding Remarks}

In a recent study, Ang et al. [4] confirm the ubiquity of a puzzling negative idiosyncratic volatility (IVOL) effect [1] in 23 developed countries, including the seven largest developed economies (G7). However, in their study, they also report that among G7 countries not only did France show a decrease in the magnitude of the idiosyncratic volatility coefficient when idiosyncratic volatility was computed using a local Fama-French model instead of a world Fama-French model, but also the idiosyncratic volatility coefficient turned insignificant, indicating the absence of an IVOL effect. We investigate this further in this study. We also investigate the behavior of aggregate idiosyncratic and market volatility in the French stock market in as much as Campbell, et al. [20] report evidence of an increasing trend in idiosyncratic volatility in the U.S. relative to market volatility which is disputed by both Brandt, et al. [21] and Bekaert, et al. [41]. 
We find that both idiosyncratic and market volatility do not exhibit long-term trends. Instead their patterns are consistent with regime switching behavior similar to that in the U.S. and other developed countries. Though we initially find a negative IVOL effect in the French stock market which is robust in bi-variate Fama-MacBeth regressions, the negative IVOL effect promptly disappears when we control for these well-known effects simultaneously.

We add new evidence to the mounting results questioning the ubiquity of the IVOL effect which highlights the importance of country verification of so-called anomalies in the US, even in developed markets.

\section{Acknowledgements}

We thank two anonymous reviewers for their constructive comments. We also wish to thank the participants of the World Business, Finance, and Management Conference in December, 2014, Auckland, New Zealand for their comments and suggestions on earlier versions of this paper.

\section{References}

[1] Ang, A., Hodrick, R.J., Xing, Y. and Zhang, X. (2006) The Cross-Section of Volatility and Expected Returns. Journal of Finance, 61, 259-299. https://doi.org/10.1111/j.1540-6261.2006.00836.x

[2] Levy, H. (1978) Equilibrium in an Imperfect Market: A Constraint on the Number of Securities in a Portfolio. American Economic Review, 68, 643-658.

[3] Merton, R. (1987) A Simple Model of Capital Market Equilibrium with Incomplete Information. Journal of Finance, 42, 483-510. https://doi.org/10.1111/j.1540-6261.1987.tb04565.x

[4] Ang, A., Hodrick, R.J., Xing, Y. and Zhang, X. (2009) High Idiosyncratic Volatility and Low Returns: International and Further U.S. Evidence. Journal of Financial Economics, 91, 1-23. https://doi.org/10.1016/j.jfineco.2007.12.005

[5] Bali, T.G. and Cakici, N. (2008) Idiosyncratic Volatility and the Cross-Section of Expected Returns. Journal of Financial and Quantitative Analysis, 43, 29-58. https://doi.org/10.1017/S002210900000274X

[6] Bali, T.G., Cakici, N. and Levy, H. (2008) A Model-Independent Measure of Aggregate Idiosyncratic Risk. Journal of Empirical Finance, 15, 878-896. https://doi.org/10.1016/j.jempfin.2008.02.002

[7] Huang, W., Liu, Q., Rhee, S.G. and Zhang, L. (2010) Return Reversal, Idiosyncratic Risk, and Expected Returns. Review of Financial Studies, 23, 147-168. https://doi.org/10.1093/rfs/hhp015

[8] Malkiel, B. and Xu, Y. (2004) Idiosyncratic Risk and Security Returns. Paper Presented in AFA 2001 New Orleans Meetings.

[9] Spiegel, M. and Wang, X. (2006) Cross-Sectional Variation in Stock Returns: Liquidity and Idiosyncratic Risk. Working Paper, Yale University.

[10] Divatopolous, D., Doran, J. and Peterson, P. (2008) The Information Content in Implied Idiosyncratic Volatility and the Cross-Section of Stock Returns: Evidence from the Options Markets. Journal of Futures Markets, 28, 1013-1116. https://doi.org/10.1002/fut.20327

[11] Fu, F. (2009) Idiosyncratic Risk and the Cross-Section of Expected Returns. Journal 
of Financial Economics, 91, 24-37. https://doi.org/10.1016/j.jfineco.2008.02.003

[12] Chua, C.T., Goh, J. and Zhang, Z. (2010) Expected Volatility, Unexpected Volatility, and the Cross-Section of Stock Returns. Journal of Financial Research, 33, 103-123. https://doi.org/10.1111/j.1475-6803.2010.01264.x

[13] Wei, S.X. and Zhang, C. (2006) Idiosyncratic Risk Does Not Matter: A Re-Examination of the Relationship between Average Returns and Average Volatilities. Journal of Banking and Finance, 29, 603-621. https://doi.org/10.1016/S0378-4266(04)00050-0

[14] Fink, J., Fink, K.W., Grullon, G. and Weston, J.P. (2010) What Drove the Increase in Idiosyncratic Volatility during the Internet Boom? Journal of Financial and Quantitative Analysis, 45, 1273-1279. https://doi.org/10.1017/S0022109010000487

[15] Pukthuanthong-Le, K. and Visaltanachoti, N. (2009) Idiosyncratic Volatility and Stock Returns: A Cross Country Analysis. Applied Financial Economics, 19, 1269-1281. https://doi.org/10.1080/09603100802534297

[16] Suss, S. (2012) The Pricing of Idiosyncratic Risk: Evidence from the Implied Volatility Distribution. Financial Markets and Portfolio Management, 24, 247-267. https://doi.org/10.1007/s11408-012-0183-4

[17] Liu, B., Di Iorio, A. and De Silva, A. (2016) Equity Fund Performance: Can Momentum Be Explained by the Pricing of Idiosyncratic Volatility? Studies in Economics and Finance, 33, 359-376. https://doi.org/10.1108/SEF-04-2016-0081

[18] Aboulamer, A. and Kryzanowski, L. (2016) Are Idiosyncratic Volatility and MAX Priced in the Canadian Market? Journal of Empirical Finance, 37, 20-36. https://doi.org/10.1016/j.jempfin.2016.02.005

[19] Gu, M., Kang, W. and Xu, B. (2018) Limits of Arbitrage and Idiosyncratic Volatility: Evidence from China Stock Market. Journal of Banking and Finance, 86, 240-258.

[20] Campbell, J.Y., Lettau, M., Malkiel, B.G. and Xu, Y. (2001) Have Individual Stocks Become More Volatile? An Empirical Exploration of Idiosyncratic Risk. Journal of Finance, 56, 1-43. https://doi.org/10.1111/0022-1082.00318

[21] Brandt, M.W., Brav, A., Graham, J. and Kumar, A. (2010) The Idiosyncratic Volatility Puzzle: Time Trend or Speculative Episodes? Review of Financial Studies, 23, 863-899. https://doi.org/10.1093/rfs/hhp087

[22] Bekaert, G., Hodrick, R. and Zhang, X. (2012) Aggregate Idiosyncratic Volatility. Journal of Financial and Quantitative Analysis, 47, 1155-1185. https://doi.org/10.1017/S0022109012000543

[23] Wikipedia (2017) Euronext. https://en.wikipedia.org/wiki/Euronext

[24] Euronext (2017) We Are Euronext. https://www.euronext.com/event

[25] Bunzel, H. and Vogelsang, T. (2005) Powerful Trend Function Tests That Are Robust to Strong Serial Correlation, with an Application to the Prebisch-Singer Hypothesis. Journal of Business and Economic Statistics, 24, 381-394. https://doi.org/10.1198/073500104000000631

[26] Fama, E. and French, K. (1993) Common Risk Factors in the Returns on Stocks and Bonds. Journal of Financial Economics, 33, 3-53. https://doi.org/10.1016/0304-405X(93)90023-5

[27] Fama, E. and French, K. (1996) Multifactor Explanations of Asset-Pricing Anomalies. Journal of Finance, 51, 55-84. https://doi.org/10.1111/j.1540-6261.1996.tb05202.x

[28] Jegadeesh, N. and Titman, S. (1993) Returns to Buying Winners and Selling Losers: Implications for Stock Market Efficiency. Journal of Finance, 48, 65-91. 
https://doi.org/10.1111/j.1540-6261.1993.tb04702.x

[29] Jegadeesh, N. (1990) Evidence of Predictable Behaviour of Security Returns. Journal of Finance, 45, 881-898. https://doi.org/10.1111/j.1540-6261.1990.tb05110.x

[30] Lehmann, B. (1990) Fads, Martingales, and Market Efficiency. Quarterly Journal of Economics, 105, 1-28. https://doi.org/10.2307/2937816

[31] Kong, G.W. and Kong, D.M. (2015) Institutional Investors' Trading in Speculation: Evidence from China. South African Journal of Economics, 83, 617-631. https://doi.org/10.1111/saje.12073

[32] Dickey, D. and Fuller, W. (1979) Distribution of the Estimator for Autoregressive Time Series with a Unit Root. Journal of the American Statistical Association, 74, 427-431.

[33] Duncan, A. and Kabundi, A. (2014) Global Financial Crisis and Time-Varying Volatility Movement in World Equity Markets.South African Journal of Economics, 82, 531-550. https://doi.org/10.1111/saje.12033

[34] Vogelsang, T. (1998) Trend Function Hypothesis Testing in the Presence of Serial Correlation. Econometrica, 66, 603-621. https://doi.org/10.2307/2998543

[35] Nartea, G.V., Wu, J. and Liu, Z.T. (2013) Does Idiosyncratic Volatility Matter in Emerging Markets? Evidence from China. Journal of International Financial Markets, Institutions and Money, 27, 137-160. https://doi.org/10.1016/j.intfin.2013.09.002

[36] Stotz, O., Wanzenried, G. and Dohnert, K. (2010) Do Fundamental Indexes Produce Higher Risk-Adjusted Returns than Market Cap Indexes? Evidence for European Stock Markets. Financial Markets and Portfolio Management, 24, 219-243. https://doi.org/10.1007/s11408-010-0135-9

[37] Brockman, P. and Yan, X. (2006) The Time-Series Behavior and Pricing of Idiosyncratic Volatility: Evidence from 1926-1962. Working Paper, University of Missouri.

[38] Drew, M., Malin, M., Naughton, T. and Veeraraghavan, M. (2006) Idiosyncratic Volatility and Security Returns: Evidence from Germany and United Kingdom. Studies in Economics and Finance, 23, 80-93. https://doi.org/10.1016/j.intfin.2013.09.002

[39] Newey, W.K. and West, K.D. (1987) A Simple, Positive Semi-Definite, Heteroscedasticity and Autocorrelation Consistent Covariance Matrix. Econometrica, 55, 703-708. https://doi.org/10.2307/1913610

[40] Morel, C. (2001) Stock Selection Using a Multi-Factor Model-Empirical Evidence from the French Stock Market. European Journal of Finance, 7, 312-334. https://doi.org/10.1080/13518470110071137

[41] Bekaert, G. and Harvey, C. (2000) Foreign Speculators and Emerging Equity Markets. The Journal of Finance, 55, 565-613. https://doi.org/10.1111/0022-1082.00220 


\section{Appendix}

Appendix 1. Description of the sample stocks.

\begin{tabular}{|c|c|c|c|c|c|}
\hline Date & $\begin{array}{c}\text { Numbers of shares } \\
\text { in the sample }\end{array}$ & $\begin{array}{l}\text { Average annual } \\
\text { return }\end{array}$ & $\begin{array}{l}\text { Average annual } \\
\text { return skewness }\end{array}$ & MV & BTM \\
\hline 1992 & 302 & -0.0679 & -0.0606 & 659.40 & 1.2294 \\
\hline 1993 & 315 & 0.3504 & 0.1170 & 869.30 & 0.9202 \\
\hline 1994 & 334 & -0.0420 & 1.5075 & 860.21 & 0.8775 \\
\hline 1995 & 347 & -0.0887 & 0.2484 & 822.05 & 1.0251 \\
\hline 1996 & 546 & 0.1760 & 0.2888 & 732.71 & 0.9577 \\
\hline 1997 & 627 & 0.1466 & -0.1441 & 894.61 & 0.8297 \\
\hline 1998 & 737 & 0.0906 & -1.0023 & 1023.12 & 0.7306 \\
\hline 1999 & 803 & 0.2144 & 0.7631 & 1569.31 & 0.7169 \\
\hline 2000 & 861 & -0.0060 & 1.0624 & 1697.98 & 0.6730 \\
\hline 2001 & 855 & -0.2597 & -0.9607 & 1407.38 & 1.0782 \\
\hline 2002 & 795 & -0.3234 & -0.6019 & 1179.36 & 1.0866 \\
\hline 2003 & 767 & 0.2030 & -0.3242 & 1333.34 & 0.8656 \\
\hline 2004 & 739 & 0.1849 & -0.1132 & 1527.50 & 0.7226 \\
\hline 2005 & 746 & 0.2304 & 0.2720 & 1911.92 & 0.7028 \\
\hline 2006 & 811 & 0.1571 & -0.4414 & 2128.03 & 0.6415 \\
\hline 2007 & 825 & -0.0404 & -0.3787 & 2241.29 & 0.6677 \\
\hline 2008 & 756 & -0.6634 & -0.5796 & 1353.78 & 1.3195 \\
\hline 2009 & 751 & 0.2683 & 0.2072 & 1735.53 & 1.0409 \\
\hline 2010 & 732 & 0.0831 & -0.8367 & 1707.00 & 1.1484 \\
\hline 2011 & 698 & -0.1384 & -0.7039 & 1528.81 & 1.2056 \\
\hline 2012 & 685 & -0.2805 & 0.4579 & 1490.94 & 1.2830 \\
\hline
\end{tabular}

